\title{
Implementasi Pengendalian Robot Mobil Pencari Target Dan
}

\section{Penghindar Rintangan}

\author{
Toibah Umi Kalsum ${ }^{1 *}$, Khairil ${ }^{2}$ \\ ${ }^{1}$ Program Studi Rekayasa Sistem Komputer Fakultas Ilmu Komputer Universitas Dehasen, *cicik.umie@gmail.com \\ ${ }^{2}$ Program Studi Sistem Informasi Fakultas Ilmu Komputer Universitas Dehasen, khairil@unived.ac.id
}

\begin{abstract}
AbstraK
Robots are useful to help humans in performing jobs that require high precision, substantial labor, repetitive and dirty work, and high-risk or dangerous jobs. Those are the high-risk human jobs that a robot can do. Wheeled robots have the ability to go to the targeted position. Proportional control is used to control the movement of robots. In addition, the robot will also be equipped with PI control method to adjust the actual wheel speed of the robot. The block diagram of the obstacle-driven avoider robot consists of push button, rotary encoder, ultrasonic sensor, Atmega, IC L298D, DC Motor and Light. The results of the obstacle-driven avoider robot, wheeled robots have the ability to run in accordance with the desired black line. Proportional control is used to control the movement of robots. In addition, the robot will also be equipped with ultrasonic sensors to set the robot in avoiding obstacles. Based on the results of testing and analysis that have done, it is suggested that there is tool that can be provided to develop a more sophisticated technology like adding sensors or more features.
\end{abstract}

Kata kunci: Robot, Wheel, Atmega, Sensor

\section{Pendahuluan}

Teknologi merupakan cara untuk mendapatkan suatu kualitas yang lebih baik, lebih mudah, lebih murah, lebih cepat dan lebih menyenangkan. Salah satu teknologi berkembang pesat pada saat ini adalah teknologi di bidang robotik [1].

Robot bermanfaat tuntuk membantu manusia dalam melakukan pekerjaan yang membutuhkan ketelitian tinggi, membutuhkan tenaga besar, pekerjaan yang berulang dan kotor, dan pekerjaan yang beresiko tinggi atau berbahaya.Salah satu pekerjaan manusia yang beresiko tinggi yang dapat dilakukan oleh robot adalah pemadam kebakaran.Pekerjaan pemadam kebakaran membutuhkan reaksi yang cepat karena masalah kebakaran dapat dikurangi apabila sumber api dapat ditemukan dan dipadamkan dalam waktu yang singkat [2].

Teknologi robot mobil sebagai alat bantu manusia terus berkembang sekarang ini untuk menjawab tantangan itu. Mulai dari tujuan hiburan, robot mobil cerdas, alat pengangkut barang, hingga misi luar angkasa telah menggunakan teknologi robot mobil sebagai alat bantu manusia. Dengan melihat peran robot mobil yang semakin besar, dituntut adanya metode-metode baru untuk penyempurnaan teknologi robot mobil ini [3].

Pada robot mobil, terutama yang memiliki misi "menuju sasaran" dengan tipe penggerak differensial biasanya hanya terdapat satu kontroler close loop untuk mengendalikan posisi robot. Sedangkan kendali kecepatan ke roda kanan dan kiri untuk mengatur pergerakan robot dilakukan secara open loop atau dengan kata lain kecepatan roda aktual tidak di perhatikan. Mengingat banyak sekali hal yang mempengaruhi kecepatan putar roda seperti tidak identiknya kinerja kedua roda, berat robot dan lintasan robot yang berupa tanjakan atau turunan, membuat metode pengendalian kecepatan secara open loop ini sangat merugikan [4].

Dalam penelitian ini, penulis mencoba menganalisa sistem kerja dan pembuatan program robot beroda penghalang rintangan. Robot beroda mempunyai kemampuan untuk menuju target posisi yang diingikan. Pengendali proporsional digunakan untuk mengontrol pergerakan robot. Selain itu robot juga akan dilengkapi dengan metode kontrol PI untuk mengatur kecepatan roda aktual robot. Berdasarkan latar belakang di ataspenulis mengangkat judul "Implementasi Pengendalian Robot Mobil Pencari Target dan Penghindar Rintangan".

\section{KERANGKA TEORITIS}

\section{A. Pengertian Robot}

Kata robot berasal dari bahasa Czech, robota yang berarti pekerja, mulai menjadi populer ketika seorang penulis berbangsa Czech (Ceko), Karl Capek, membuat pertunjukan dari lakon komedi yang ditulisnya pada tahun 1921 yang berjudul RUR (Rossum 's Universal Robot) [4].

Robot secara umum dapat diartikan sebuah sistem yang terdiri dari hardware dan software yang dapat melakukan tugas tertentu dari manusia. Robot dirancang oleh manusia untuk membantu bahkan menggantikan kegiatan manusia yang butuh ketelitian dan beresiko tinggi [5] .

Robot dapat diartikan sebagai sebuah mesin yang dapat bekerja secara terus menerus baik secara otomatis maupun terkendali. Robot yang digunakan untuk membantu tugas-tugas manusia mengerjakan hal yang sulit atau dilakukan manusia secara langsung. Misalnya menangani material radio aktif, merakit mobil dalam industri perakitan mobil, menjelajah planet mars, sebagai media pertahanan atau perang, dan sebagainya. Pada 
dasarnya dilihat dari struktur dan fungsi fisiknya (pendekatan visual) robot teridiri dari dua bagian, yaitu non-mobile robot dan mobile robot. Kombinasi keduanya menghasilkan kelompok konvensional (mobile dan nonmobile) contohnya mobile manipulator, walking robot, dan non konvensional (humanoid, animaloid, extraordinary). Saat ini robot selainuntuk membantu pekerjaan manusia juga digunakan sebagai hiburan [6].

\section{B. MikrokontrolerAtmega}

Mikrokontroler merupakan suatu alat elektronika digital yang mempunyai masukan dan keluaran serta kendali dengan program yang bias ditulis dan dihapus dengan cara khusus, cara kerja mikrokontroler sebenarnya membaca dan menulis data [7].

Mikrokontroler yang biasa digunakan pada board Arduino. Atmega32 merupakan mikrokontroler keluarga AVR 8 bit. Beberapa tipe mikrokontroler yang sama denganAtmega 8 ini antara lain Atmega8535, Atmega16, Atmega32, Atmega 328, yang membedakan antara mikrokontroler antara lain adalah, ukuran memori, banyaknya GPIO (pin input/output), peripherial (USART, timer, counter, dan lain-lain). Dari segi ukuran fisik, Atmega328 memiliki ukuran fisik lebih kecil dibandingkan dengan beberapa mikrokontroler di atasnya.

Namun untuk segi memori dan periperial lainnya Atmega328 tidakkalahdengan yang lainnya karena ukuran memori dan periperial relative sama dengan Atmega8535, Atmega32, hanya saja jumlah GPIO lebih sedikit dibandingkan mikrokontroler diatasnya. Pin out IC mikrokontrolerAtmega16 yang berpackage DIP [7].

\section{METODOLOGI}

Metode penelitian yang digunakan adalah metode penelitian Eksprimen. Metode penelitian bersifat validation atau menguji, yaitu bagaimana analisa kerja sensor jarak akan bekerja secara otomatis mendeteksi keberadaan rintangan didepannya yang selanjutnya data akan dikirim ke atmega. Kemudian menganalisa kerja sensor cahaya dalam membaca garis hitam sehingga robot beroda tetap berjalan pada lintasan.

\section{A. Blok Diagram Global}

Diagram blok global yang digunakan dalam penelitian ini adalah sebagai berikut dapat dilihat pada Gambar 1 di bawah ini.

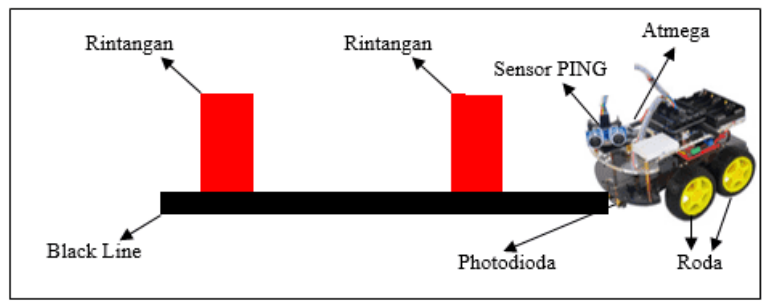

Gambar 1. Blok Diagram Global

Sensor Ultrasonik (PING) berfungsi untuk mendeteksi keberadaan benda didekatnya. Rangkaian utama yaitu rangkaian Atmega yang berfungsi untuk mengolah data. Cahaya untuk mendeteksi garis. Black line atau garis hitam sebagai jalur lintasan. Rintangan berfungsi untuk menghadang laju robot, apakah robot dapat menghindar atau tidak. Roda berfungsi untuk pergerakkan dari robot.

\section{B. Diagram Blok Rangkaian Alat}

Gambar 2 di bawah ini adalah gambar diagram rangkaian robot beroda penghindar rintangan. Diagram blok rangkain robot beroda penghindar rintangan terdiridaripush button, rotary encoder, sensor ultrasonik, Atmega, IC L298D, Motor DCdan Cahaya.

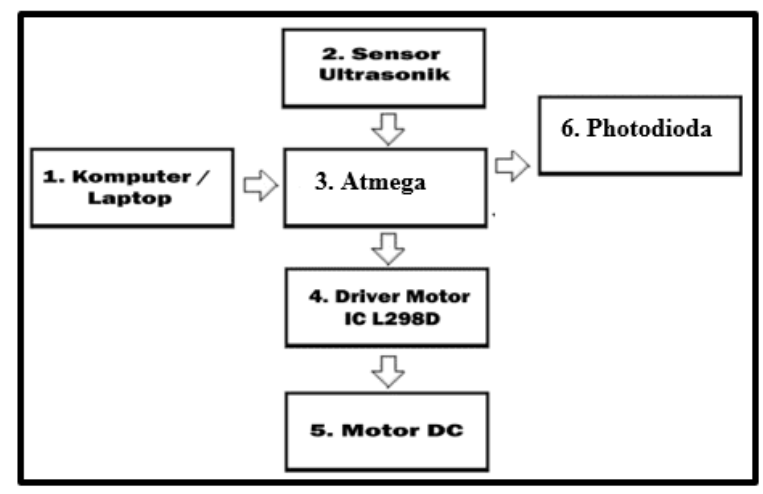

Gambar 2. Diagram Blok Rangkaian Alat

Komputer / Laptop digunakan sebagai perancangan program untuk rancang bangun robot beroda. Sensor ultrasonik berfungsi mendeteksi keberadaan benda didekatnya tanpa kontak fisik. Atmega berfungsi sebagai pengolahan data berupa program yang di upload dari komputer dengan menggunakan serial USB. Driver Motor IC L293D digunakan untuk membuat driver $H$ bridge untuk 2 buah motor DC (Direct Current). Motor DC berfungsisebagaipenggerak robot beroda penghindar rintangan. Sensor cahaya untuk mendeteksi garis.

\section{Desaian Rangkaian}

Gambar 3 di bawah ini merupakan gambar desaian rangkaian yang dibuat menggunakan software Proteus Isis 8.1, dapat dilihat pada gambar di bawah ini.

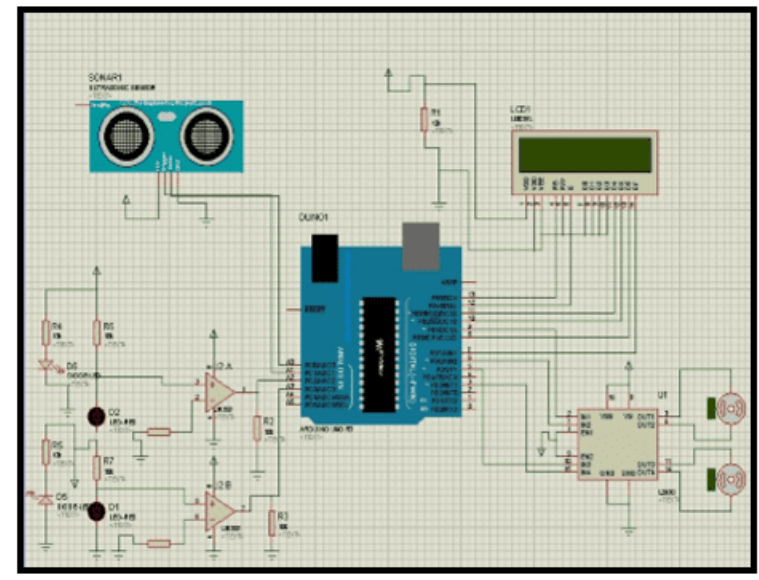

Gambar 3. Desaian Rangkaian

Atmega memiliki 14 digital pin untuk input/output (ataubiasaditulis $\mathrm{I} / \mathrm{O}, \quad$ dimana 6 pin di antaranyadapatdigunakansebagai output PWM), 6 pin 
input analog menggunakan crystal $16 \mathrm{MHz}$, koneksi USB, jack listrik header ICSP dantombol reset. Sensor Ultrasonik berfungsi untuk mendeteksi keberdaan benda didekatnya tanpa kontak fisik. Sensor Ultrasonik sering memancarkan elektromagnetik atau berkas radiasi elektromagnetik. Sensor cahaya untuk mendeteksi garis.

\section{Prinsip Kerja}

Prinsip kerja robot beroda penghindar rintangan yaitu sensor jarak akan bekerja secara otomatis mendeteksi keberadaan rintangan didepannya yang selanjutnya data akan dikirim ke atmega. Kemudian menganalisa kerja sensor cahaya dalam membaca garis hitam sehingga robot beroda tetap berjalan pada lintasan.

\section{HASIL DAN PEMBAHASAN}

\section{A. Hasil Robot Beroda}

Hasil analisa robot beroda penghalang rintangan, robot beroda mempunyai kemampuan untuk berjalan sesuai dengan garis hitam yang diinginkan. Pengendali proporsional digunakan untuk mengontrol pergerakan robot. Selain itu robot juga akan dilengkapi dengan sensor ultrasonik untuk mengatur robot dalam menghindari rintangan. Dalam pembuatan robot beroda penghalang rintangan untuk tampilan robot beroda tampak atas dapat dilihat pada gambar 4 di bawah ini.

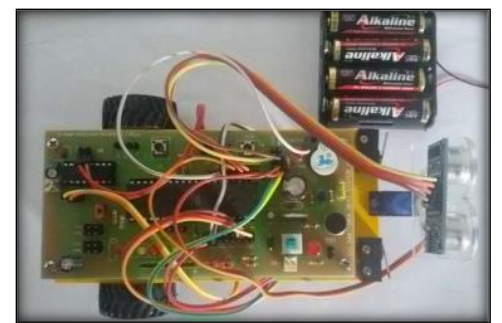

Gambar 4. Tampilan Robot Beroda Dari Atas

Berdasarkan gambar 4 diatas, robot beroda dan catu daya menggunakan battere dengan daya $6 \mathrm{va}$, dan menggunakan catu daya 3va untuk menjalankan 2 buah sensor.

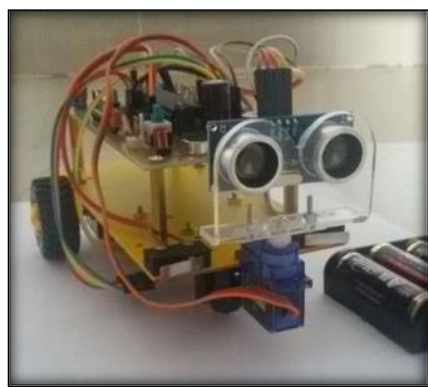

Gambar 5. Tampilan Robot Beroda Dari Depan

Berdasarkan gambar 5 diatas, robot beroda di ambil gambar dari depan, terlihat sensor ultrasonik seolah-olah menjadi mata bagi robot beroda dan robot beroda memiliki arus catu daya menggunakan battere dengan daya 6va, dan menggunakan catu daya $3 \mathrm{va}$ untuk menjalankan 2 buah sensor.

\section{B. Hasil Program}

Hasil yang di peroleh dalam menggunakan aplikasi NS one berupa listing program. Dimana kode program yang akan dikirim pada mikrokontroller dengan menggunakan bahasa pemograman java. Listing program dapat dilihat pada gambar 6 dan untuk lebih jelas dapat dilihat pada gambar dibawah ini.

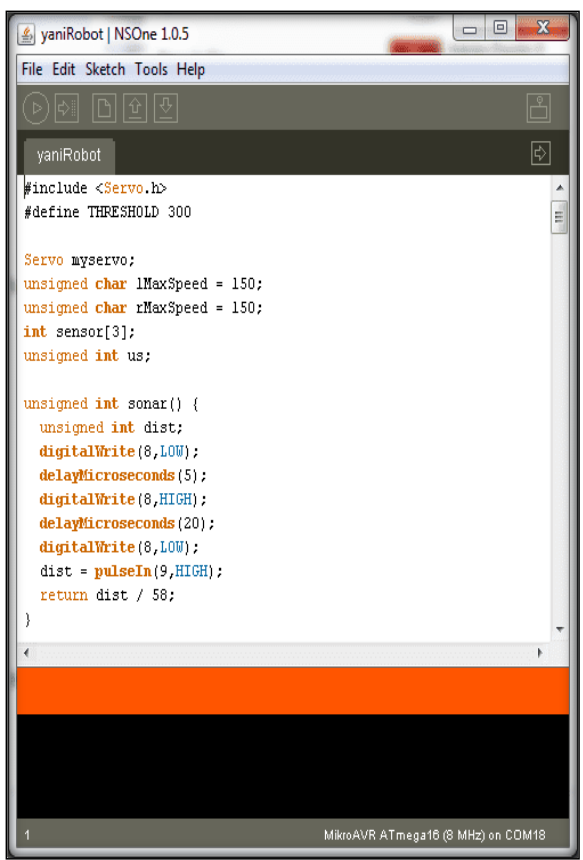

Gambar 6. Listing Program NS One

\section{Pengujian Robot}

Adapun tampilan Ns one dalam pembuatan robot beroda adalah sebagai berikut :

1. Tampilan Awal Ns One

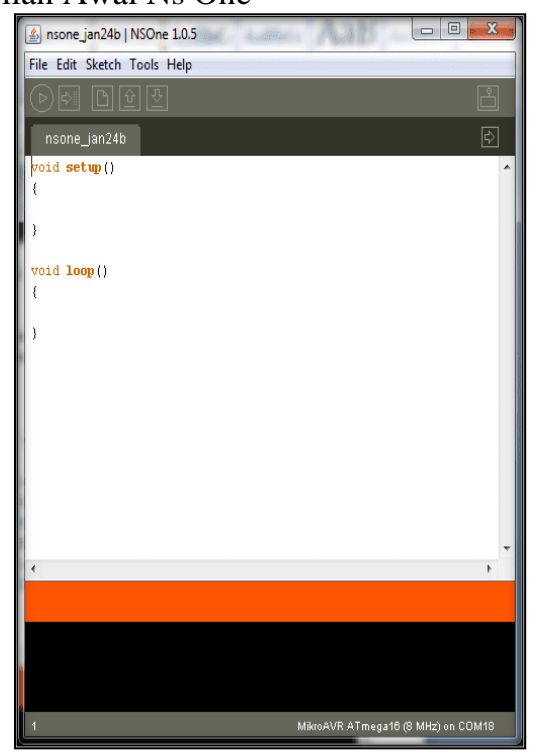

Gambar 7. Tampilan awal NS One

2. Mengetik program dengan Ns One 


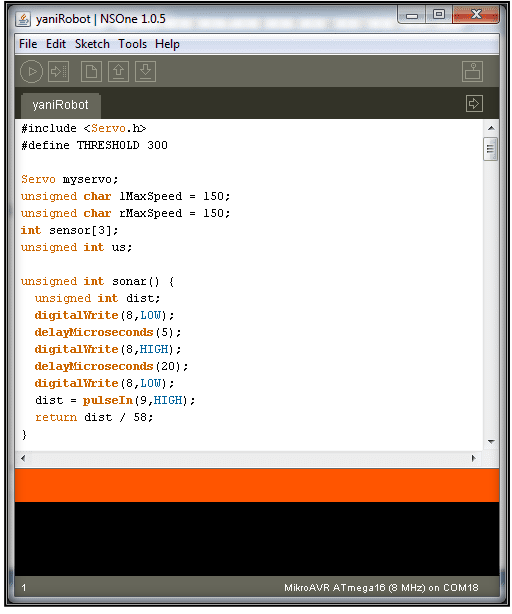

Gambar 8. Kode Program

3. Proses Verify

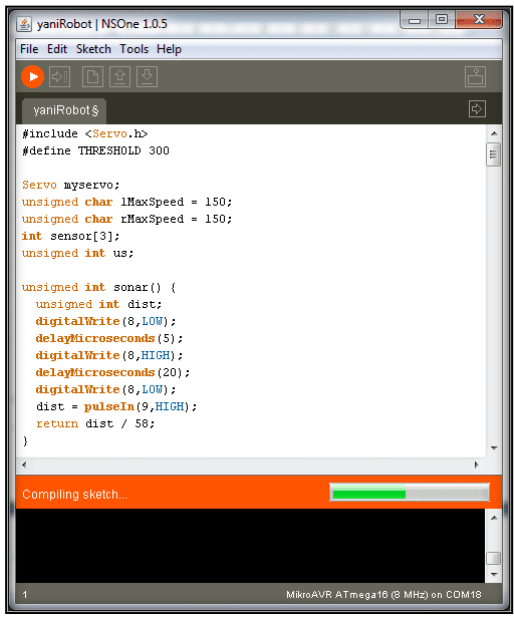

Gambar 9. Proses Verify

4. Hasil Verify

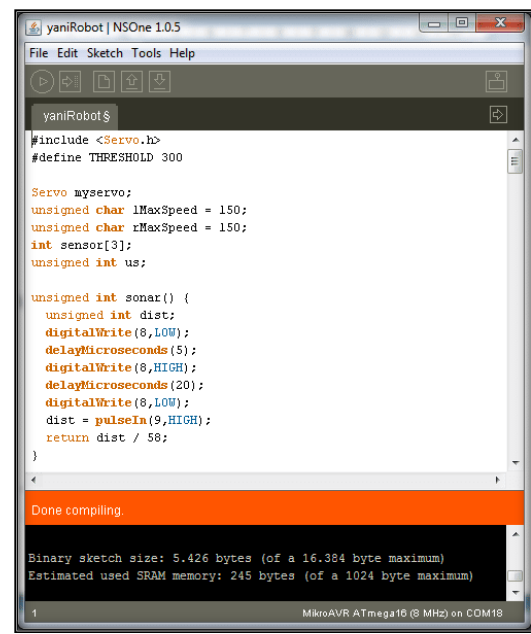

Gambar 10. Hasil Verify

\section{Pengujian Sensor Touch}

Hubungkan pin dari touch sensor dengan port input digital yang telah disediakan. Dalam contoh berikut, touch sensor dihubungkan dengan port A6 (pin 30) dan A7 (pin 31). Konfigurasi dari touch sensor adalah active
LOW dan pada pin A6 dan A7 sudah terpasang resistor pullup eksternal. Ketika salah satu touch sensor tertekan, LED yang terhubung dengan port C2 (pin 18) akan menyala selama 2 detik. Adapun cuplikan koding program adalah sebagai berikut :

void setup ()

\{

pinMode (30, INPUT) ;

pinMode (31, INPUT) ;

pinMode (18, OUTPUT) ;

\}

void loop ()

\{

if ( digitalRead(30) $==0$ | |

digitalRead (31) $==0$ )

\{

digitalWrite (18,HIGH) ;

delay (2000);

digitalWrite (18, LOW);

\}

\section{E. Pengujian Komunikasi Serial}

Dalam praktik, komunikasi serial antara robot dapat dilakukan melalui USB hardware programmer atau pin RX/TX yang tersedia pada board. Bila menggunakan USB ISP hardwareprogrammer K125R, pastikan saklar padanya berada pada posisi S. Jangan lupa untuk memindahkannya kembali ke posisi $\mathrm{P}$, ketika akan menggunakannya untuk memrogram. Bila menggunakan USB ASP, pastikan memasang modul USB/Serial yang disertakan dan menghubungkannya ke pin TX/RX pada board secara bersilangan.

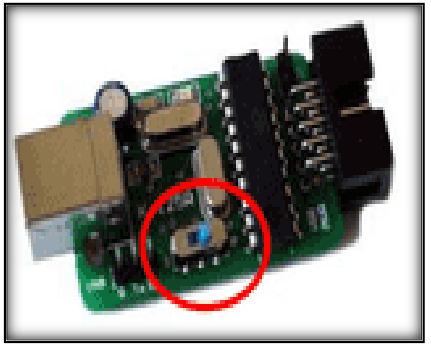

Gambar 11. Komunikasi serial

Pastikan setting baudrate di terminal laptop sudah sesuai. Dalam contoh berikut, kita menggunakan baudrate 9600 .

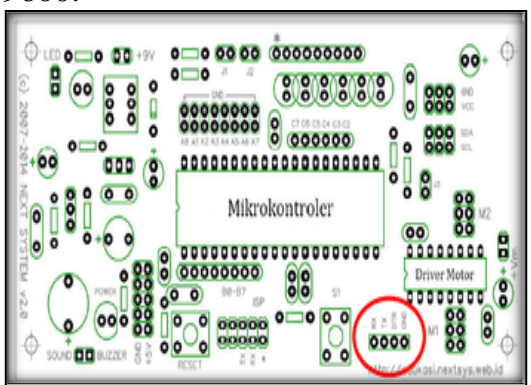

Gambar 12. Tampilan digital komunikasi serial pada mikrokontroller

\section{F. Pengujian Sensor Sound}


Dalam contoh program berikut, LED yang terhubung dengan port C2 (pin 18) akan menyala selama 2 detik ketika jari dijentikkan cukup keras di dekat mikrofon.

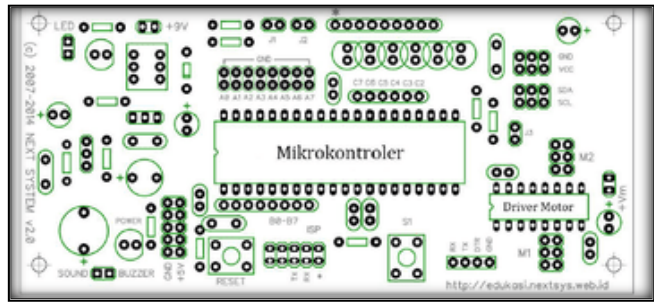

Gambar 13. Tampilan digital sound pada mikrokontroler

Adapun cuplikan koding program sensor sound adalah sebagai berikut :

void setup ()

\{

pinMode (18, OUTPUT) ;

digitalWrite (18, LOW);

\}

void loop()

\{

if ( analogRead (0) > 600)

\{

digitalWrite (18, HIGH) ;

delay (2000);

digitalWrite (18, LOW);

\}

\}

Berdasarkan cuplikan koding program diatas, Saat mendapat input berupa suara, output sound sensor akan mengayun naik turun sesuai dengan kuat lemahnya intensitas suara yang masuk.

\section{G. Pengujian Sensor Light}

Hubungkan kedua pin LDR (tidak ada polaritas) dengan port input analog yang telah disediakan, misalnya port A6 atau A7. Pada kedua pin ini terhubung dengan resistor pullup eksternal bila jumper $\mathrm{J} 1$ terpasang. Pada pin analog lain, bisa menggunakan resistor pullup internal bila diperlukan.

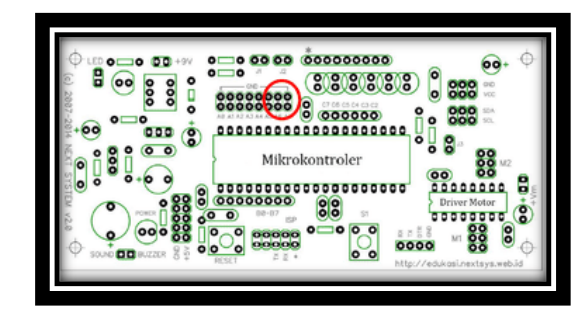

Gambar 13. Tampilan Digital Sensor Light Pada Mikrokontroller

Hubungkan kabel serial dengan komputer dan aktifkan serial monitor, kemudian perhatikan angka yang tampil ketika sensor berada di tempat gelap dan terang.

\section{H. Pengujian Sensor Line}

Hubungkan modul line sensor dengan port yang telah disediakan. Pastikan kabel penghubung dipasangkan dalam posisi yang bersesuaian, misal A0, A1 dan A2.

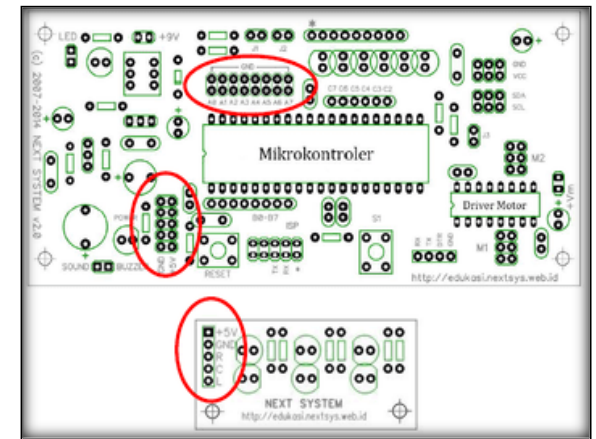

Gambar 14. Tampilan Digital Sensor Line Pada Mikrokontroller

Untuk modul line sensor, pada tampak atas (sisi komponen), urutan dari kiri ke kanan adalah : +5V, GND, A2 (L), A1 (C), A0 (R). Urutannya sudah dibuat bersesuaian dengan port terkait pada board (perhatikan port pada board yang diberi lingkaran merah di atas). Program berikut akan menampilkan bacaan sensor garis pada Serial Monitor setiap 2 detik. Perhatikan nilai yang tampil ketika sensor dihadapkan pada bidang putih (terang) dan bidang hitam (gelap).

\section{Pengujian Sensor Ultrasonik}

Sensor ultrasonik HC-SR04 memiliki 4 pin: VCC, Trigger, Echo dan GND. Pin Trigger diberikan pulsa minimal $10 \mathrm{uS}$ untuk memerintahkan sensor untuk mulai mengukur. Hasil pengukuran, dalam bentuk pulsa, dilaporkan melalui pin Echo, dengan formula Jarak $(\mathrm{cm})$ = lebar pulsa (uS) / 58 .

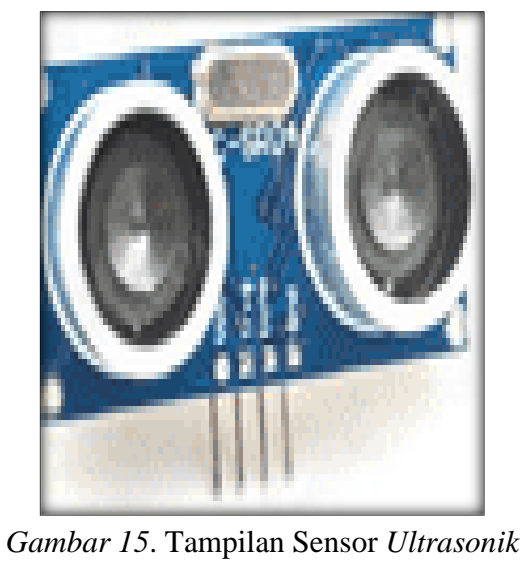

Dalam contoh berikut, sensor ultrasonik akan membaca jarak secara berulang-ulang dengan jeda 1 detik. Hasil pembacaan dikirim melalui jalur serial, dan dapat dilihat melalui program terminal. Hubungkan pin VCC, GND, Trigger dan Echo dari modul Ultrasonik dengan pin VCC, GND, pin PB0 dan PB1 pada board robot

\section{J. Pengujian Sistem}

Dari serangkai penelitian yang dilakukan mulai dari awal, maka didapat hasil seperti pada Tabel 1 Hasil Pengujian Robot Beroda Penghindar Rintangan, dapat dilihat pada tabel di bawah ini. 
TABEL 1

Aturan Pemformatan Teks

\begin{tabular}{|c|c|c|}
\hline No & Pengujian & Hasil \\
\hline 1 & $\begin{array}{l}\text { Pengujian Sensor } \\
\text { Ultrasonik }\end{array}$ & $\begin{array}{l}\text { Robot dapat menghindari } \\
\text { rintangan setinggi } 10 \mathrm{~cm} \\
\text { dan lebar } 5 \mathrm{~cm}\end{array}$ \\
\hline 2 & $\begin{array}{l}\text { Pengujian Sensor } \\
\text { Cahaya }\end{array}$ & $\begin{array}{l}\text { Berjalan mengikuti garis } \\
\text { hitam yang dibuat. }\end{array}$ \\
\hline 3 & $\begin{array}{l}\text { Pada Lintasan } \\
\text { sepanjang } 60 \mathrm{~cm} \\
\text { dan belok ke } \\
\text { kanan sepanjang } \\
60 \mathrm{~cm}\end{array}$ & $\begin{array}{l}\text { Ketika robot di POWER } \\
\text { ON, akan terdengar bunyi } \\
\text { BEEP tiga kali. Setelah } \\
\text { tombol S1 ditekan, akan } \\
\text { terdengar bunyi BEEP } \\
\text { tiga kali lagi, dan program } \\
\text { akan lanjut ke proses di } \\
\text { dalamnya, yakni: } \\
\text { 1) Bila tidak terlihat } \\
\text { penghalang < } 8 \mathrm{~cm}, \\
\text { robot akan bergerak } \\
\text { mengikuti garis. } \\
\text { Kecepatan dapat diatur } \\
\text { dengan menyesuaikan } \\
\text { nilai 1MaxSpeed dan } \\
\text { rMaxSpeed. Nilai } \\
\text { kecepatan antara } 0 \text { - } \\
\text { 255cm3, dalam } \\
\text { program menggunakan } \\
\text { kecepatan maksimum } \\
\text { 150cm3, atau } 60 \% \text {. } \\
\text { Bila melihat } \\
\text { penghalang < } 8 \text { cm, } \\
\text { robot akan bergerak } \\
\text { mengitari penghalang. } \\
\text { Pergerakan ini pun } \\
\text { dapat disesuaikan jari- } \\
\text { jari putarannya. } \\
\text { Mengatur putaran } \\
\text { untuk menghindari } \\
\text { benda dengan lebar } 5 \\
\text { cm. Selanjuta, robot } \\
\text { akan melanjutkan } \\
\text { pergerakan mengikuti } \\
\text { garis. }\end{array}$ \\
\hline
\end{tabular}

\section{KESIMPULAN DAN SARAN}

\section{A. Kesimpulan}

Setelah perancangan sistem dan pengujian sistem, maka dapat diambil beberapa kesimpulan tentang robot beroda penghalang rintangan, yaitu Robot beroda mempunyai kemampuan untuk berjalan sesuai dengan garis hitam yang diinginkan. Robot juga akan dilengkapi dengan sensor ultrasonikuntuk mengatur robot dalam menghindari rintangan setinggi $<8 \mathrm{~cm}$, robot akan bergerak mengitari penghalang. Pergerakan ini pun dapat disesuaikan jari-jari putarannya. Mengatur putaran untuk menghindari benda dengan lebar $5 \mathrm{~cm}$. Dari hasil pengujian sistem, terdapat 2 pengujian yaitu engujian Sensor Ultrasonik, Robot dapat menghindari rintangan setinggi $10 \mathrm{~cm}$ dan lebar $5 \mathrm{~cm}$. Sedangkan pengujian Sensor Cahaya berjalan mengikuti garis hitam yang dibuat.

\section{B. Saran}

Berdasarkan hasil pengujian dan hasil analisa yang telah penulis lakukan, maka penulis memberikan saran agar alat dapat dikembangkan lagi memiliki teknologi yang lebih canggih. Seperti melakukan penambahan sensor, untuk menambahkan fitur lagi.

\section{Pernyataan}

1. Saya menyatakan bahwa makalah saya yang berjudul Implementasi Pengendalian Robot Mobil Pencari Target Dan Penghindar Rintangan adalah asli dan tidak pernah dipublikasikan di tempat lain.

2. Dengan publikasi, saya kirimkan hak cipta kepada Jurnal Amplifier. Transfer hak cipta termasuk di dalamnya hak untuk mereproduksi fotografi untuk artikel sejenis dan terjemahannya. Hal ini juga termasuk dalam hak untuk memasukkan artikel dalam sistem komputer untuk disebarluaskan dalam jaringan internet dsb.

\section{Bengkulu, 25 Oktober 2021}

Penulis,

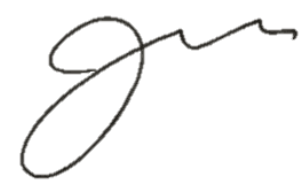

Toibah Umi Kalsum, M. KOM

\section{Contoh Penulisan Referensi}

N. Rachman, Zaini, Fathur; Yanti, "Robot Penjejak Ruangan Dengan Sensor Ultrasonik Dan Kendali Ganda Melalui Bluetooth," J. Teknol. Terpadu, Vol. 4, No. 2, Pp. 114-119, 2016, Doi: Https://Doi.Org/10.32487/Jtt.V4i2.

[2] E. Suryatini, Fitria ; Kustija, Jaja ; Haritman, "Robot Cerdas Pemadam Api Menggunakan Ping Ultrasonic Range Finder Dan Uvtron Flame Detector Berbasis Mikrokontroler Atmega 128," ELECTRANS, vol. 12, no. 1, pp. 29-38, 2013, [Online]. Available: https://ejournal.upi.edu/index.php/electrans/article/vie wFile/1865/1261.

[3] A. Ilamsyah; Setyawan, Ikhsan, Hendri; Syahfitri, "Robot Pencari Benda Menggunakan Perintah Suara Berbasis Arduino Uno," Cerita, vol. 2, no. 2, pp. 206216, 2017, [Online]. Available: https://ejournal.raharja.ac.id/index.php/cerita/article/vi ew/658/584.

[4] I. D. R. Kurniawan I. L;Setiawan, "Pengendalian Robot Mobil Pencari Target Dengan Kemampuan Menghindari Rintangan," Universitas Diponegoro, 2011.

[5] R. Setiawan, "Pengembangan Robot Pendeteksi Objek Berdasarkan Warna Dengan Sensor Kamera Sebagai Media Pembelajaran," Unersitas Negeri Yogyakarta, 
2012.

[6] R. Dewi, Kesuma, "Perancangan dan Pembuatan Ackerman Mobile Robot dengan Kendali PID untuk Menghindari Halangan Berbasis Hybrid System.," Stikom Surabaya, 2012.

[7] H. Erwansyah, Kamil ; Herriyance; Winata, "Rancang
Bangun Alat Pengaman Kandang Sapi Menggunakan Sensor Ldr Berbasis Mikrokontroler," Saintikom, vol. 15, no. 03, pp. 117-128, 2016, [Online]. Available: https://prpm.trigunadharma.ac.id/public/fileJurnal/hp9 s5 JURNAL KAMIL ERWANSYAH SEPT 2016.pdf. 